\title{
Correlation Between Maternal Serum Thyroid Profile And Preeclampsia At or Above 36 wks Gestation A Prospective Comparative Observational Study
}

\author{
Dr. Rusha Haldar ${ }^{1}$,Dr. Partha Pratim Sinhababu ${ }^{2}$,Dr. Prof. Gita Basu Banerjee ${ }^{3}$, \\ Dr. Debesh Ray ${ }^{4}$ \\ ${ }^{1,2}$ Jr Resident, Obst \& Gynae, Bankura Sammilani Medical College, Bankura, West Bengal, India \\ ${ }^{3}$ Professor, Obst \& Gynae, Bankura Sammilani Medical College, Bankura, West Bengal, India \\ ${ }^{4}$ Associate Professor, Biochemistry, Medical College, Kolkata, West Bengal, India
}

\begin{abstract}
:
Purpose of the study: The present study examines whether maternal thyroid hormone function during later weeks of gestation is related with preeclampsia in a cross sectional view.

Methods: This hospital based observational, prospective comparative study was conducted in the Dept. of Obs and Gynae , Bankura Sammilani Medical College and Hospital, Bankura, India ( under West Bengal University of Health Sciences) from April 2014 to March 2015. 200 primigravida mothers attending OPD/admitted in indoor matched with age and parity of gestational age 36 to 41 wks were included in the study in two groups Group A- Normotensive $(N=100)$ And Group B-Preeclamptic $(N=100)$. Thyroid hormones triiodothyronine (t3), thyroxine (t4) and thyroid stimulating hormone (tsh) were evaluated in both the groups.

Results: Mean serum TSH in the normotensive group (A) was $1.69 \pm 0.34 \mu \mathrm{IU} / \mathrm{ml}$ vs. mean serum TSH in the preeclamptic group $(B)$ was $4.39 \pm 1.85 \mu \mathrm{IU} / \mathrm{ml} .(P<0.001)$, which is statistically significant. However, the mean value of thyroid hormones was in normal range. The risk of having LOW BIRTH WEIGHT (LBW) babies was 2.78 times more in mothers with elevated TSH level in comparison to mothers with normal TSH level.

Conclusion: The current study revealed that elevated TSH level is associated with preeclampsia and low birth weight $(L B W)$ babies. So there is a strong potential to use maternal serum TSH level to predict preeclampsia and $L B W$ babies.
\end{abstract}

Keywords: preeclampsia, serum thyroid profile

\section{Introduction}

Hypertensive disorders represent the most common medical complication of pregnancy affecting between 7 to $15 \%$ of all gestations and account for about a quarter of all antenatal admissions [1]. The International Society for the Study of Hypertension in Pregnancy has adopted the following research definition of preeclampsia: (1) de novo hypertension after 20 weeks of gestation, (2) properly documented proteinuria of greater than $300 \mathrm{mg} / 24 \mathrm{hr}$, and (3) both hypertension and proteinuria disappearing postpartum. Severe preeclampsia is defined as either severe hypertension i.e. systolic $\mathrm{BP} \geq 160 \mathrm{~mm}$ of $\mathrm{Hg}$ or diastolic $\mathrm{BP} \geq 110 \mathrm{~mm}$ of $\mathrm{Hg}$ or if there is multi organ involvement such as pulmonary oedema, seizures, oliguria $(<500 \mathrm{~mL} / 24-\mathrm{hr}$ period), thrombocytopenia (platelet count $<100,000 / \mathrm{mm} 3$ ), abnormal liver enzymes in association with persistent epigastric or right upper quadrant pain, or persistent severe central nervous system symptoms (altered mental status, headaches, blurred vision, or blindness) [2].

Physiological changes of pregnancy cause the thyroid gland to increase production of thyroid hormones by 40 to 100 percent to meet maternal and fetal needs [3]. Anatomically the thyroid gland undergoes moderate enlargement during pregnancy caused by glandular hyperplasia and increased vascularity [4]. The secretion of T4 and T3 is not similar for all pregnant women. Approximately a third of women experience relative hypothyroxinemia, preferential T3 secretion. Thyrotropin or thyroid stimulating hormone (TSH) currently plays a central role in screening and diagnosis of many thyroid disorders. Serum thyrotropin levels in early pregnancy decrease because of thyroid stimulation from the weak TSH effects of hCG [5]. TSH does not cross the placenta. Studies on preeclamptic patients have revealed that $16.7 \%$ and $43.7 \%$ of subjects were sub-clinical and overt cases of hypothyroidism respectively during pregnancy [6]. Preeclamptic women show high incidence of hypothyroidism that might correlate with the severity of preeclampsia $[7,8,9]$.

\section{Aims And Objectives}

The present study examined whether maternal thyroid hormone function during later weeks of gestation is related with preeclampsia in a cross sectional view. 


\section{Specific objectives:}

1. Measurement of maternal serum T3, T4 and TSH level at or after 36 weeks of gestational age and to find out their correlation with preeclampsia

2. To find out whether maternal serum TSH level has any increased propensity for preeclampsia

3. To determine fetal outcome in respect of different obstetrical parameters like amniotic fluid index, gestational age, mode of delivery and newborn birth weight.

\section{Materials And Methods}

This hospital based observational, prospective comparative study was conducted in the Department of Obstetrics and Gynaecology, Bankura Sammilani Medical College and Hospital, Bankura ( under West Bengal University of Health Sciences), India from April 2014 to March 2015.

\section{Selection of cases:}

Two hundred primigravida mothers attending OPD or admitted in indoor matched with age and parity of gestational age 36 to 41 wks were included in the study in two groups: GROUP A- NORMOTENSIVE $(\mathrm{n}=100)$ and GROUP B- PREECLAMPTIC. $(\mathrm{n}=100)$

Women taking levothyroxine or antithyroid medications during pregnancy, multifetal pregnancy, Preterm pregnancy, fetal anomalies, eclamptic mothers, women in labour and known hypertensive - (essential or secondary), mothers with known heart disease, diabetes mellitus or other medical disorders and women with IUFD were excluded from this study.

\section{Study Techniques}

After proper counselling and informed consent from each antenatal mother selected in our study population, details of the clinical history including age, parity, menstrual history and clinical examination regarding presentation, position, amount of liquor, were done meticulously. Blood pressure was measured by Mercury Sphygmomanometer. Transabdominal USG was performed for assessment of gestational age, amount of liquor, presentation and position of the fetus. Supportive 'Thyroid profile was measured by taking $5 \mathrm{ml}$ of venous blood sample and separate blood samples were sent to Biochemistry department of BSMCH, Bankura by standard laboratory procedure. Another $5 \mathrm{ml}$ of venous blood was taken and sent to Pathology dept for analysis of haemoglobin and platelet and to Biochemistry dept for analysis of ALT, urea and creatinine.

\section{Parameters Assessed:}

1) Obstetric parameters: Term was assessed in two ways, from the first day of the last menstrual period and from an ultrasound scan in the first trimester. If there was discrepancy of more than 7 days between the two measurements, gestational age was assessed from the ultrasound scan. Gestational age was expressed in weeks. Amniotic fluid index was also calculated from ultrasound scan at term Blood investigations like haemoglobin, platelet, ALT, creatinine, urine for protein were performed.Measurements of systolic blood pressure (SBP), diastolic blood pressure (DBP), mean arterial pressure (MAP) were recorded. Mode of delivery was noted.

\section{2) Thyroid Parameters:}

Maternal serum T3, T4 and TSH level were measured in preeclamptic mothers and normotensive mothers at or after 36 weeks of gestational age who were admitted in the hospital and were not in labour, after overnight fast. TSH was measured by ELISA method at the Department of Biochemistry, Bankura. 5 ml venous blood was collected for this purpose. The blood was allowed to clot and centrifuged @ $2000 \mathrm{rpm}$ for 10 minutes. Clear straw coloured fluid was pipetted out for esitmation of T3, T4 and TSH. Serum samples which were not used for immediate analysis were stored at $2-8^{\circ} \mathrm{C}$. ELISA kit was used for T3, T4 and TSH estimation. Normal reference ranges for T3: $0.5-1.85 \mathrm{ng} / \mathrm{ml}$.

Normal reference ranges for T4: $4.4-10.8 \mu \mathrm{g} / \mathrm{dl}$

Normal reference ranges for TSH: $0.3-3 \mu \mathrm{IU} / \mathrm{ml}$ in $3^{\text {rd }}$ trimester of pregnancy

\section{3) Fetal Parameters:}

Measurement of the birth weight of the baby

Fetal and perinatal death

\section{Results And Discussion}

Statistical analysis was performed by using the STATISTICAL PACKAGE OF SOCIAL SCIENCE Version 20.0 (SPSS). Statistical analysis was done by means, standard deviations and frequencies. Significance of different variables was performed by chi square test, $\mathrm{t}$-test in different variables and $\mathrm{p}$ value less than 0.05 was considered as significant. Continuous variables like blood pressure were measured as mean \pm variance and 
compared across groups using independent ' $\mathrm{t}$ ' test. Normotensive mothers ( Group A ) and Preeclamptic mothers ( Group B ) showed no statistical significance in age and socioeconomic status.

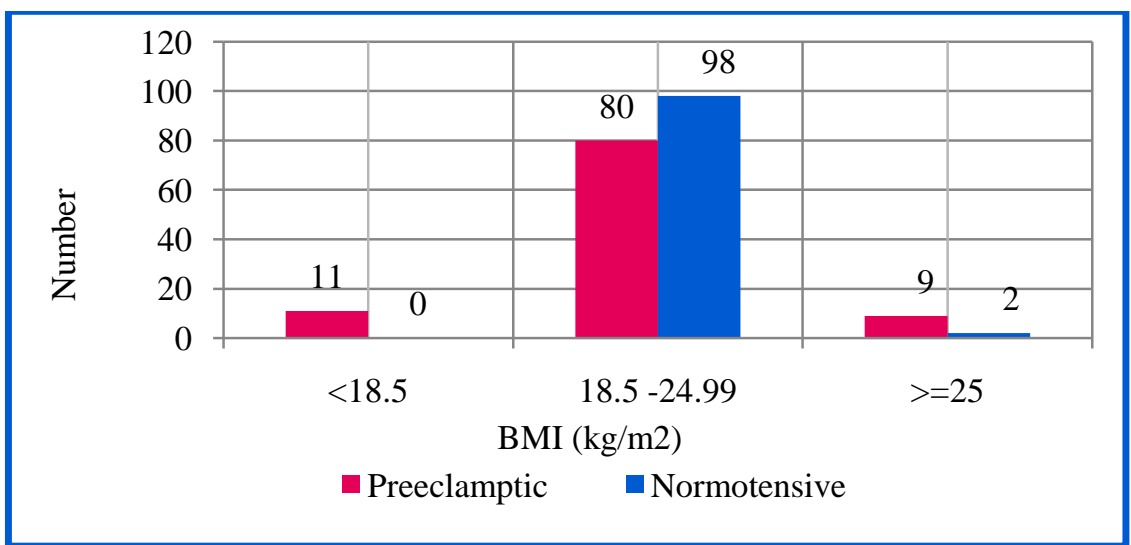

Figure 1

Figure 1 depicts detection of body mass index (BMI) in preeclamptic and normotensive pregnant mothers. $80 \%$ preeclamptic mothers and $98 \%$ normotensive have normal BMI. It is clear from the above table that higher number of preeclamptic patients was having either lower or higher BMI value compared to their counterpart. The difference was found to be statistically significant $(\mathrm{p}<0.001)$.

Table 1:

\begin{tabular}{|c|c|c|c|}
\hline \multicolumn{4}{|c|}{ Table showing relationship of clinical parameters of study groups } \\
\hline Variables & $\begin{array}{c}\text { Normotensive subjects } \\
(\mathrm{n}=100)\end{array}$ & Preeclamptic subjects (n=100) & $p$ value \\
\hline SBP & $\mathbf{1 2 5 . 6 0} \pm \mathbf{7 . 0 1}$ & $\mathbf{1 5 8 . 0 4} \pm \mathbf{1 0 . 6 8}$ & $\square \mathbf{0 . 0 0 1}$ \\
DBP & $\mathbf{7 3 . 7 0} \pm \mathbf{4 . 3 8}$ & $\mathbf{9 4 . 6 0} \pm \mathbf{3 . 2 2}$ & $\square .001$ \\
MAP & $\mathbf{9 0 . 7 2} \pm 3.83$ & $\mathbf{1 1 5 . 4 1} \pm 4.25$ & $\square .001$ \\
BMI & $\mathbf{2 2 . 0 2} \pm \mathbf{1 . 2 9}$ & $\mathbf{2 1 . 2 6} \pm \mathbf{2 . 6 3}$ & $\square 0.001$ \\
\hline
\end{tabular}

Table 2:

\begin{tabular}{|c|c|c|c|}
\hline \multicolumn{4}{|c|}{ Table showing obstetric outcome of the two groups } \\
\hline Variables & $\begin{array}{c}\text { Normotensive } \\
\text { subjects (n=100) }\end{array}$ & $\begin{array}{c}\text { Preeclamptic } \\
\text { subjects (n=100) }\end{array}$ & $p$ Value \\
\hline LSCS & 16 & 36 & $\square .001$ \\
Birth weight & $2.74 \pm 0.17$ & $2.63 \pm 0.19$ & $\square .001$ \\
\hline
\end{tabular}

Table 3:

\begin{tabular}{|c|c|c|c|}
\hline \multicolumn{4}{|c|}{ Table showing the thyroid profile of the two groups } \\
\hline Variables & $\begin{array}{c}\text { Normotensive subjects } \\
(\mathrm{n}=100)\end{array}$ & $\begin{array}{c}\text { Preeclamptic subjects } \\
(\mathrm{n}=100)\end{array}$ & $p$ Value \\
\hline TSH $(\mu \mathrm{IU} / \mathrm{mL})$ & $1.69 \pm 0.34$ & $4.39 \pm 1.85$ & 0.001 \\
T3 $(\mu \mathrm{g} / \mathrm{dL})$ & $8.91 \pm 0.47$ & $\mathbf{8 . 9 9} \pm \mathbf{0 . 6 5}$ & 0.33 \\
T4 $(\mathrm{ng} / \mathrm{mL})$ & $\mathbf{0 . 9 2} \pm \mathbf{0 . 1 1}$ & $\mathbf{0 . 9 1} \pm \mathbf{0 . 1 1}$ & $\mathbf{0 . 6 9 5}$ \\
\hline
\end{tabular}

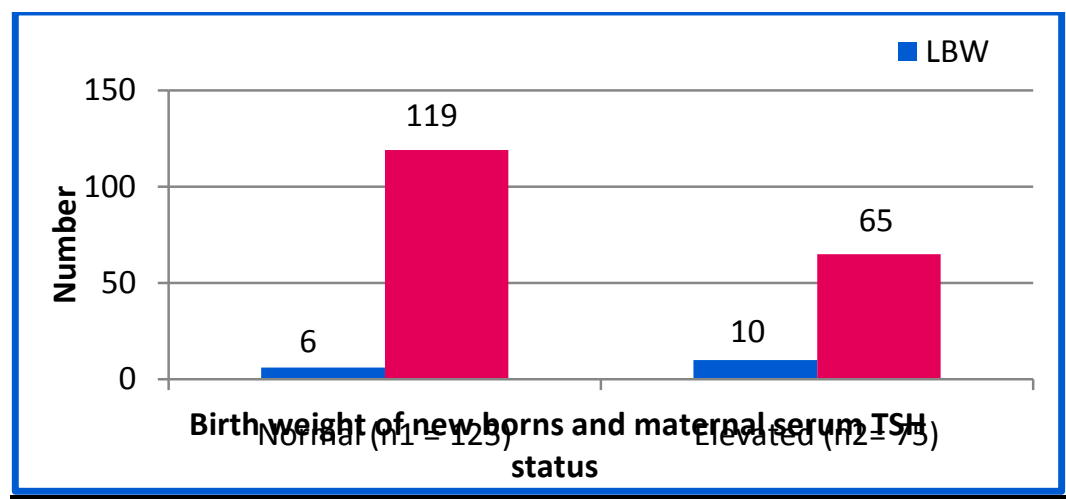

Figure 2 
Figure 2: Distribution of the birth weight of the newborns and serum TSH status in the mothers. Mothers with normal serum TSH level delivered 95.2\% normal birth weight (NBW) babies and $4.8 \%$ low birth weight (LBW) babies. Similarly, mothers with elevated serum TSH level delivered $86.66 \%$ NBW babies and $13.33 \%$ LBW babies. The risk of having LBW babies was 2.78 times more in mothers with elevated TSH level in comparison to mothers with normal TSH level ( $\mathrm{p}$ value: 0.031 ).

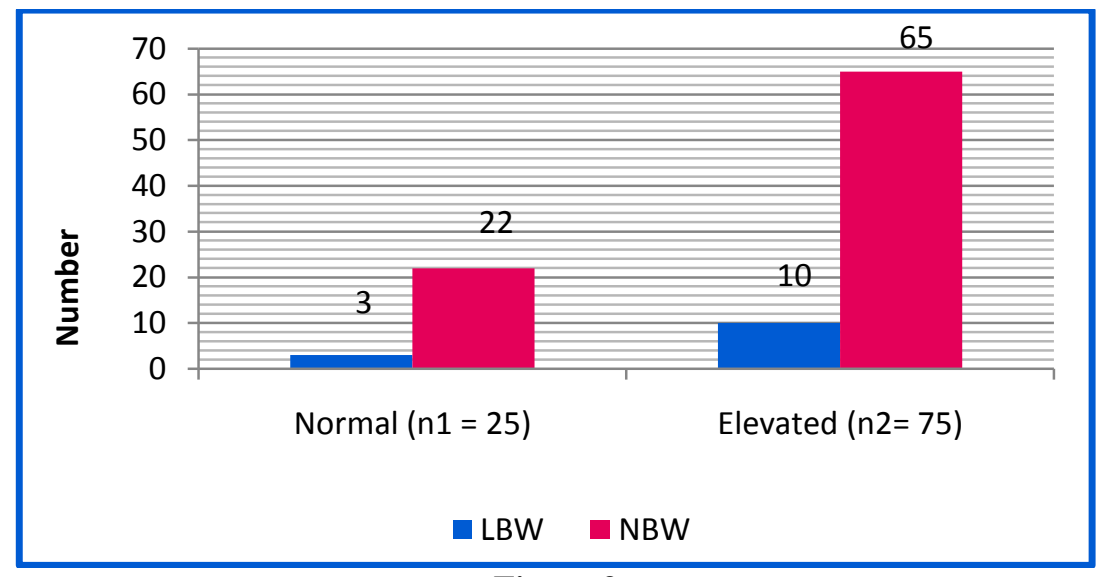

Figure 3

Figure 3: Distribution of the birth weight of the newborns and serum TSH status in the preeclamptic mothers. Preeclamptic mothers with normal serum TSH level delivered 88\% normal birth weight (NBW) babies and $12 \%$ LBW babies, whereas preeclamptic mothers with elevated serum TSH level delivered $86.6 \%$ NBW babies and $13.13 \%$ LBW babies. The risk of having LBW babies was 1.1 times more in preeclamptic mothers with elevated TSH level ( $\mathrm{p}$ value: 0.86 ).

So figures 2 and 3 imply that relative risk of having an LBW baby is more relatable to serum TSH level than to Blood Pressure. Most of the mothers had normal BMI in this study.

In the study by C.J. Lee and associates (2000) in determining the risk factors of pre eclampsia in Asian women, showed that women who had a BMI > 24.2 had a greater risk of developing pre eclampsia [10]. In another study by S Ganesh Kumar and associates (2010) it was shown that women witn BMI > 25 were at a greater risk of developing pre eclampsia [11]. Serum TSH was compared in both the groups and was found to be significantly higher in the preeclamptic group. Mean serum TSH in the normotensive group was $1.69 \pm 0.34$ $\mu \mathrm{IU} / \mathrm{ml}$ and Mean serum TSH in the pre eclamptic group was $4.39 \pm 1.85 \mu \mathrm{IU} / \mathrm{ml}$. Serum T3 and Serum T4 were also compared in both the groups. But the $\mathrm{p}$ value was not statistically significant. (p value was 0.695 for serum T3 and 0.335 for serum T4).

Our findings were in correspondence with the findings of the study conducted by Kumar et al in 2005 . In their study they evaluated thyroid hormones in 82 preeclamptic women and equal number of matched controls. They found mean TSH levels were significantly higher in preeclamptic group as compared to controls $(\mathrm{p}<0.001)$. However, mean values of thyroid hormones were in the normal range [12]. Kharb et al found that TSH and T4 levels were higher in mild preeclampsia as compared with severe preeclampsia $(P<0.001$ and $P<$ 0.01 , respectively). T3 levels were lower in preeclampsia [13]. In another study, free T4 and TSH levels were measured in 100 preeclamptic patients and were compared with free T4 and TSH levels in 101 normal pregnant women in their third trimester of pregnancy by Raoofi et al [14]. A significant difference in concentration of free T4 levels $(0.729 \pm 0.324 \mathrm{ng} / \mathrm{dl}$ versus $0.929 \pm 0.314 \mathrm{ng} / \mathrm{dl}, \mathrm{p}<0.001)$ was observed in the preeclamptic group compared with the normotensive group, but the mean TSH level was not significantly different $(2.935 \pm 1.16 \mathrm{mIU} / \mathrm{L}$ versus $2.339 \pm 1 / 15 \mathrm{mIU} / \mathrm{L}, \mathrm{p}=0.170)$. Wilson et al [15] made a secondary analysis of a prospective prenatal population-based study in which serum thyroid function analytes were measured. Pregnancy outcomes in 24,883 women were analyzed for pregnancy hypertension. The overall incidences of hypertension in pregnancy were $6.2 \%, 8.5 \%$, and $10.9 \%$ in the subclinical hyperthyroid, euthyroid, and subclinical hypothyroid groups respectively, and were found to be significant when unadjusted ( $p$ value 0.016 ). After adjusting for confounding factors, there was a significant association between subclinical hypothyroidism and severe preeclampsia (adjusted odds ratio 1.6, 95\% confidence interval $1.1-2.4 ; p$ value 0.03). Thus they concluded that women with subclinical hypothyroidism identified during pregnancy have an increased risk for severe preeclampsia when compared with euthyroid women. Ashoor et al [16] in their study concluded that impaired thyroid function may predispose to the development of late onset preeclampsia and measurement of maternal serum TSH can improve the prediction of late onset preeclampsia provided by a combination of factors in the maternal history and the measurements of MAP and uterine artery PI. Männistö et al [17] analyzed singleton pregnancies $(n=223512)$ from a retrospective US cohort, the Consortium on Safe Labor (2002-2008). 
They found that Primary hypothyroidism was associated with increased odds of preeclampsia $(\mathrm{OR}=1.47,99 \%$ $\mathrm{CI}=1.20-1.81)$, superimposed preeclampsia $(\mathrm{OR}=2.25,99 \% \mathrm{CI}=1.53-3.29)$.

But two major studies did not find any relation between subclinical hypothyroidism and gestational hypertension. Casey et al [18] studied 404 women with subclinical hypothyroidism . Pregnancies in women with subclinical hypothyroidism were 3 times more likely to be complicated by placental abruption (relative risk 3.0, $95 \%$ confidence interval 1.1-8.2). Preterm birth, defined as delivery at or before 34 weeks of gestation, was almost 2-fold higher in women with subclinical hypothyroidism (relative risk, 1.8, 95\% confidence interval1.12.9). In another study by Cleary Goldman et al [19] subclinical hypothyroidism was documented in $2.2 \%$ (240 of 10,990) in the first and $2.2 \%$ (243 of 10,990) in the second trimester. Subclinical hypothyroidism was not associated with adverse outcomes.

\section{Limitations of the study}

Free T3, free T4 could not be studied due to non availability of kits. Sample size was small with Short duration of study on uncomplicated primigravida. Neonates were not followed to monitor their developmental milestones. Early pregnancy and postpartum values of T3, T4 and TSH were not compared.

\section{Conclusion}

In this observational study, preeclamptic women had statistically significant high TSH level when compared to normotensive mothers. But serum T3, T4 levels did not show difference of statistical significance. There is potentiality of use of serum TSH as a predictor of preeclampsia. So, should TSH be included in antenatal investigations in this geographical area where preeclampsia is rampant?

It was observed that preeclamptic women with higher TSH level delivered a larger number of LBW babies. Even normotensive mothers with high TSH level had a larger number of LBW babies. SO, can TSH level be used as a predictor of LBW babies? Both the inferences from our study need multicentric approach with larger sample size for future use.

\section{Ethical compliance}

All procedures followed were according to the ethical standards of the institutional ethics committee and with the Helsinki declaration of 1975, revised in 2008. Informed consent was obtained fro each subject for being included in this study.

\section{Conflict of interest}

The authors declare that they have no conflict of interest

\section{References}

[1]. James PR, Nelson-Piercy C. Management of hypertension before, during and after pregnancy. Heart.2004; 90:1499-1504

[2]. NHBPEP (National High Blood Pressure Education Program) Working Group on High Blood Pressure. Report of the National High Blood Pressure Education Program Working Group in High Blood Pressure in Pregnancy. Am J Obstet gynecol. 2000; 183:S1-S22. Smallridge RC, Glinoer D, Hollowell JG, Brent G: Thyroid function inside and outside of pregnancy: What do we know and what don't we know?Thyroid.2005;15:54

[4]. Glinoer D, de Nayer P, Bourdoux P, et al. Regulation of maternal thyroid during pregnancy. J Clin Endocrinol Metab, 1990; 71:276.

[5]. Grossman M, Weintraub BD, Szkudlinski MW: Novel insights into the molecular mechanisms of human thyrotropin action: Structural, physiological, and therapeutic implications for the glycoprotein hormone family.Endocr.Rev1997; 18:476.

[6]. Davis, L.E., K.J. Leveno and F.G. Cunningham, 1988. Hypothyroidism complicating pregnancy. Obstet. Gynecol., 72: 108-112

[7]. Lao, T.T., R.K. Chin, R. Swaminathan and Y.M. Lam, 1990. Maternal thyroid hormones and outcome of pre-eclamptic pregnancies. Br. J. Obstet. Gynaecol., 97: 71-74.

[8]. Lao, T.T., R.K.H. Chin and R. Swaminathan, 1988. Thyroid function in pre-eclampsia. Br. J. Obstet. Gynaecol., 95: 880-883.

[9]. Kaya, E., Y. Sahin, Z. Ozkececi and H. Pasaoglu, 1994. Relation between birth weight and thyroid function in preeclampsia-eclampsia. Gynaecol Obstet. Invest., 37: 30-33.

[10]. Lee CJ, Hsieh TT, Chiu TH, Chen KC, Lo LM, Hung TH Risk factors for pre-eclampsia za :Risk Factors of Pre-Eclampsia/Eclampsia and Its Adverse Outcomes in Low- and Middle-Income Countries: A WHO Secondary AnalysisPLoS One. 2014; 9(3): e9119

[11]. S Ganesh Kumar, B Unnikrishnan, K Nagaraj, S Jayaram: Determinants of pre-eclampsia: A case-control study in a district hospital in South India Indian Journal of Community Medicine, Vol. 35, No. 4, October-December, 2010, pp. 502-505

[12]. Kumar, A., B.K. Ghosh and N.S. Murthy, 2005. Maternal Thyroid hormonal status in preeclampsia. Ind. J. Med. Sci., 59: 57-63.

[13]. Kharb, S., D. Sardana and S. Nanda, 2013. Correlation of thyroid functions with severity and outcome of Pregnancy. Ann. Med. Health Sci. Res., 3: 43-46.

[14]. Raoofi, Z., A. Jalilian, M.S. Zanjani, S.P. Parvar and S.P. Parvar, 2014. Comparison of thyroid hormone levels between normal and preeclamptic pregnancies. Med. J. Islam Repub. Iran, 28: 1-5.

[15]. Wilson, K.L., B.M. Casey, D.D. McIntire, L.M. Halvorson and F.G. Cunningham, 2012. Subclinical thyroid disease and the incidence of hypertension in pregnancy. Obstet. Gynecol., 119: 315-320.

[16]. Ashoor, G., N. Maiz, M. Rotas, N.A. Kametas and K.H. Nicolaides, 2010. Maternal thyroid function at 11 to 13 weeks of gestation and subsequent development of preeclampsia.Prenat.Diagn., 30: 1032-1038.

[17]. Mannisto, T., P. Mendola, J. Grewal, Y. Xie, Z. Chen and S.K. Laughon, 2013. Thyroid diseases and adverse pregnancy outcomes in a contemporary US cohort. J. Clin. Endocrinol.Metab., 98: 2725-2733

[18]. Casey BM, Dashe JS, Wells CE, McIntire DD, Byrd W, Leveno KJ et al . Subclinical hypothyroidism and pregnancy outcomes. Obstet Gynecol 2005; 105:239-45.

[19]. Cleary-Goldman, J., F.D. Malone, G. Lambert-Messerlian, L. Sullivan and J. Canicket al., 2008. Maternal thyroid hypofunction and pregnancy outcome. Obstet. Gynecol., 112: 85-92. 